\title{
Surgeons and HIV/AIDS: Medico-Legal Considerations
}

\author{
Osime, O.C. and D.U. Odigie
}

\begin{abstract}
The prevalence of HIV cases among patients in recent times has assumed a worrisome dimension and thus pose a great challenge to health-care providers who come in direct contact with patients' blood and other body fluids in the course of their duty. Prominent among these personnel are Surgeons and nurses. The uncertainty of patients' HIV status, inadequacy or near total absence of appropriate safety facilities for health-care providers and lack of clearly defined policies on management of HIV/AIDS in most health-care institutions pose a great challenge and makes the issue of operating on HIV positive patients topical. This paper examines the right of HIV positive patients to surgicare vis-à-vis the need to protect the Surgeon from possible transmission of infection from the patient during surgical procedures. Recommendations are also made towards achieving a regime of safe work condition and environment for surgeons, while protecting the rights of the patients.
\end{abstract}

\section{INTRODUCTION}

The increase in Human Immune Deficiency Virus (HIV) infection poses serious challenges not only to medical services, but also to legal system ${ }^{12}$. The main target of the Human Immune Deficiency virus is the host immune system and as at today, definite and permanent cure has not been identified. The virus weakens the immune system of the host making such a person vulnerable to variou forms of infections, which ordinarily should not cause infection in a healthy individual. The virus may be present in an individual and yet

KEY WORDS: HIV positive patients, the Surgeon, legal rights

aDr. Osime, O.C. FMCS, FICS, Consultant Surgeon, Department of Surgery, University of Benin, Benin City. ${ }^{b} D . U$. Odigie Esq., IU.B(Hons) IUM, MPA B.L Lecturer, Faculty of Law, University of Benin, Benin City.

Correspondence to: Dr. Osime O.C. Department of Surgery, UBTH, PMB 1111, Benin City. Edo State, Nigeria. Email: clementosime@yahoo.com Phone: 08023332674, $052-603071$. no symptoms are manifested. This individual is said to be HIV positive. When symptoms of the virus begin to manifest in the individual, the person is considered to have the Acquired Immune Deficiency Syndrome. It is a syndrome because it is a whole lot of signs and symptoms depicting the ravaging effect of the virus. Some of such features manifested are persistent fever, persistent cough, marked weight loss, various forms of skin infections, etc. Thus, not all HIV positive patients are considered to be AIDS patients, but virtually all AIDS patients are usually HIV positive,

Various modes of transmission have been identified. They include sexual intercourse, sharing of sharp objects (e.g, blades) blood transfusion, needle pricks (e.g, during surgical procedures), contact of skin whose continuity is breached with body fluids and secretions from an infected person, etc. As a result of the devastating effect of the virus, many people are usually worried when relating with HIV/AIDS patients. The exaggerated and undue fear that doctors and other health

() CMS UNIBEN JMBR 2006; 5 (1) : 51-57 
workers have of being infected by patients with HIV has led to widespread and gross human rights abuses in clinical management and treatment. Abuses include the refusal of treatment, testing patients for HIV without their informed or any consent, insisting upon HIV testing devoid of diagnostic or therapeutic justification, and widespread breaches of confidentiality. The implication is that everyone in the society often neglects the victim of the disease, particularly those in the health profession.

Doctors owe professional duty of care to everyone irrespective of the nature of the disease. This is professional, ethical and possibly legal ${ }^{5}$. However, often times some doctors and other health workers decline treatment to HIV/AIDS patients for several reasons ${ }^{6}$. The purpose of this paper is to stimulate further awareness about the rights of the HIV/AIDS patients to get medical care irrespective of the diagnosis and to seek for ways to legally empower those patients who may be denied treatment on account of being positive for HIV/AIDS. The paper also emphasises the need for the surgeon to be protected.

\section{The Surgeons' Risks Vis-À-Vis HIV Positive Patients}

Surgery is that arm of medicine that treats patients mainly by using the hands. Surgical procedures vary from minor to major operations and in either of these; the Surgeon by necessary implication is bound to come in contact with the patients' blood and other body secretions. For example splashes of blood from an infected patient can get to mucous membranes or skin of the surgeon. The Surgeon may also pierce his hands with a needle or other instruments being used on the patient. In orthopaedic surgery for example, a piece of bone may pierce the surgeon's hands. Consequently, the Surgeon is usually uncomfortable attending to the HIV/ AldS patients for fear of being infected and it is not unusual therefore that some Surgeons in different grades are unwilling to offer surgical treatment to HIV/AIDS patients whose cases deserve surgical attention. The risk of the surgeon getting infected from an infected patient during surgical procedure is put at about 0.3-0.5\%2. Unfortunately, most hospitals in Nigeria from primary to tertiary health institutions do not have a definite policy on the surgical care of the patient with HIV/AIDS. Consequently, the policy regarding the responsibility for management therefore seems to be predicated on the personal preference or prejudice of Surgeons that varies from one individual to the other. ${ }^{6-8}$ It is submitted that this position is wrong and needs to be addressed by way of legislation.

\section{Medical and Legal Issues Arising From a Surgeon's Refusal To Treat a HIV Patient}

A lot of legal, ethical, moral and medical issues will need to be addressed. It is perhaps apt to commence the discussion on the ways the HIV screening is done because this is usually the beginning of the battle between the healthcare providers and the patients. It is common knowledge today that most Surgeons screen their patients for HIV before commencement of surgical care. In some instances patient's consent is obtained, while in others no due regard is given to the patients consent. Even where consent is obtained, the consent is not properly obtained and this kind of consent cannot be said to be valid9,10. For the consent to be valid, it has to be an informed consent, where the patient is given all the details regarding the test to be carried out ${ }^{11}$. The natural question that will follow is: when the patients are told the implications of the investigation (and with the present attitude of most Surgeons being unwilling to operate on them), will the patients still be willing to submit themselves for the investigation. The obvious answer appears to be that most of them will not be willing to do the investigation. Two issues arise from this, for those

( CMS UNIBEN JMBR 2006; 5 (1) : 51-57 
that are HIV positive; some Surgeons will not like to operate on them. Also, for those that refuse the investigation, the Surgeon will also be unwilling to operate on such patients. The legal issues that readily flow from this scenario, includes:

(i) Whether the Surgeon can compel a patient to do HIV screening;

(ii) Where the HIV test is positive, is the Surgeon justified in law should he refuse to treat the patient?

(iii) Where a Surgeon insists on knowing the HIV status of the patient, can the patient also request for the HIV status of the Surgeon?

The above issues shall be answered seriatim.

(1) The Surgeon has no right to compel a patient to undergo HIV screening test before a surgery is performed on him. It is not yet universally accepted to screen all patients for HIV infection ${ }^{12}$. However, the policy of screening all patients who require blood transfusion is recommended. This goes a long way in saving the surgeon the embarrassment or liability for a transfused patient who tests positive for HIV long after a transfusion of screened blood ${ }^{13}$. Routine screening should not be done with the aim of denying a positive patient treatment ${ }^{14}$. Ideally, where the patient is screened with his or her consent, he or she should be told the result; whether positive or negative for $\mathrm{HIV}$. In the study done in Port Harcourt ${ }^{15}$, only 3 patients out of the 26 that tested positive for HIV were informed of the results. Confidentiality of the patients result will also need to be stressed. Unfortunately, there is widespread abuse of the issue of confidentiality in disclosing a patient's status and several studies have attempted to proffer ways of correcting this anomaly $\mathrm{y}^{16,17}$. However, in the United States of America, there are specific regulations specifying confidentiality of patients' information ${ }^{18}$. In Nigeria, there appears to be nothing on ground to protect the patient in this direction. Most of our patients are not even aware of their rights and thus may not be in a position to seek redress against a doctor who divulges any information regarding him/her without his/her consent. Many other writers have frowned at the idea of revealing patients HIV status without consent ${ }^{16,17,18}$. It constitutes an outright breach of patient's right to privacy. In some countries today, the patients can sue the doctor for damages (and damages awarded) if there is abuse of their rights in terms of confidentiality. But inNigeria, it is hardly ever so. It should be noted however, that there are equally some controversies whether the doctor should not inform the society of the status of the patient in certain instances in order to protect the society ${ }^{19}$.

(ii) A doctor has no legal, moral or professional right to refuse to treat a patient on account of HIV status. Clinicians in developing countries rely barely on self-regulations in making ethical judgments or at least attempt to conform to poorly enforced ethical standards in clinical practice established by their institutions. Many doctors in such countries have refused surgery on HIV positive patients with impunity for two major reasons mainly;
(a) Absence of any clear-cut policy on management of the HIV positive patients by the surgeon in most health institutions.
(b) Lack of awareness by patients on their
right to medical or surgical treatments.

It is appropriate at this juncture, to reemphasise that doctors have a paramount duty to save lives. Failure to perform this duty amounts to failure to defend the integrity of

( CMS UNIBEN JMBR 2006; 5(1): 51-57 
the profession and failure to meet the demands of the professional calling. It has been asserted that physicians have special legal obligations because society has granted them special privileges. Annas is also of this opinion and he supports delineation and enforcement of ethical obligations by organised medicine, state licensing boards, hospitals and medical schools. ${ }^{20}$ In particular, a Surgeon should under no circumstances refuse to perform a surgery if the operation becomes necessary to save the life of the patient. A refusal amounts to deprivation of right to life as recognised by statutes and other International Conventions ${ }^{21-24}$.

Section 33 of the constitution of the Federal Republic of Nigeria 1999 provides:

Every person has a right to life, and no one shall be deprived intentionally of his life, save in execution of the sentence of a court in respect of a criminal offence of which he has been found guilty in Nigeria. ${ }^{25}$

Failure to perform surgery in order to save life amounts to an intentional deprivation of the right to life, and constitutes a breach of the constitutional provision, which provides: Part of the fundamental objectives and principles of states is the deliberate effort to safeguard the health and safety of citizens. Sections 17 (3) (a) and (c) of the 1999 constitution provides:

the state shall direct its policy towards ensuring that. . . the health, safety and welfare of all persons in employment are safeguarded and not endangered or abused.. there are adequate medical and health facilities for all persons. ${ }^{26}$

The right to health is not expressly provided for by the constitution, but is by necessary implication encapsulated in the provision for right to life, as stated by World Health Organization:

Human health is essential for sustainable development since without health, human (- CMS UNIBEN JMBR 2006; 5 (1): 51-57 beings would not be able to engage in development, combat poverty and care for their environment. ${ }^{27}$

Children infected with HIV during their birth are in a peculiar situation. The peculiarity of their case is predicated on the fact that their situations have made them become victims of the circumstances of their birth (the blame of which no one can attribute to them). The refusal by a Surgeon to carry out a surgical procedure on such a baby amounts to subjecting him to discrimination by reason of the circumstances of the baby's birth. The doctor could thus be liable to the baby or compelled to perform the surgery under section 42 (2) of the constitution of the Federal Republic of Nigeria, 1999 which provides:

No citizens of Nigeria shall be subjected to any disability or depravation merely by reason of the circumstances of his birth. ${ }^{28}$

Consequently, a Surgeon in the public service could be compelled under the constitution to perform his duty, by an order of Mandamus or where death results as a result of his failure to perform the surgery, the baby's parents can seek a remedy against the doctor for a breach of this constitutional right.

Thus, from the foregoing, it is pertinent to note that a patient diagnosed to have HIV/ AIDS ought to be treated like every other patient. The doctor has no right to discriminate against patients with HIV/AIDS in terms of treatment (whether surgical or medical). A surgeon' s discrimination against HIV positive patients is illegal and morally and ethically wrong. Another question that deserves consideration is "what are the remedies available to patient who is refused treatment due to the fact that he or she is HIV/AIDS positive?". There is yet to be (to the author's knowledge) any judicial pronouncement on the remedies available to a patient who has been denied surgical treatment on account of his HIV status. This is probably due to the 
absence of any specific legislation on this topical issue. The judiciary will obviously need to stand up to its responsibility in defining clearly how a patient may seek redress should he be under this circumstance.

Granted that patients have their rights under the law as aforesaid, it should be noted however that Surgeons are humans and also enjoy the right to be protected while performing his duties. Presently it is not mandatory to determine a patients HIV status before surgery. This situation creates a doubt in the mind of the Surgeon as to his safety while operating on the patient giving the possibility of accidental needle pricks or contact with patient's body fluids. It is suggested that where such accidental contacts occur, the patient should be subjected to immediate HIV screening test to deciding on whether or not to commence post exposure prophylaxis for the Surgeon. The need for such exceptional situation of mandatory screening becomes imperative in order to avoid placing the Surgeon on post exposure prophylaxis (with its attendant side effects), which might turn out to be needless if the patient is HIV negative. However, where the patient turns out to be HIV positive, the Surgeon should be commenced on post exposure prophylaxis. It has been suggested that post-exposure prophylaxis should be commenced within one hour of exposure for maximum benefit. ${ }^{29}$ Unfortunately, most health institutions are unable to complete the HIV screening test within the suggested time frame, let alone commencing post exposure prophylaxis. Furthermore, there is a clear situation of lack of policy guidelines regarding post exposure prophylaxis in most health institutions. It is suggested that functional and adequate screening facilities should be put in place for rapid HIV screening. It is submitted that statutory provisions should be enacted making it mandatory to health care institution to have clear-cut policies on adequate commencement of post exposure prophylaxis devoid of bureaucratic bottle-necks. A Surgeon will be justified for refusing to operate on HIV positive patients in the absence of a functional post exposure prophylaxis and other ancillary facilities which ought to be in place for his protection. ${ }^{30}$ This view was given credence by Denning L.J. in General Cleaning Contractors Ltd. V Christmas (1953) A.C. 180, where he stated:

If employers employ men on this dangerous work for their own profit, they must take proper steps to protect them, even if they are expensive. If they cannot afford to provide adequate safeguards, then they should not ask them to do it at all. It is not worth the risk. ${ }^{31}$

(iii) The last issue to be addressed is whether a patient has a right to know the surgeon's HIV status before surgery. While it is more likely that a Surgeon will get infected through positive patients, cases have been reported where HIV positive Surgeons infected patients who were hitherto HIV negative before the surger $y^{32,}{ }^{33}$. Consequently, equity demands that if a surgeon can ask a patient to declare his HIV status, the patient should also be at liberty to ask the surgeon to declare his status. This position however is fraught with a lot of bottlenecks. For example, a Surgeon that operates once a week cannot practically undergo HIV screening before every operation. This is relevant because somebody who is HIV negative today may test positive for HIV tomorrow. An attempt to resolve this quagmire may require a policy to determine how Surgeons can ascertain their HIV status at all material times and declare such to a patient who may want to know. If a surgeon is HIV positive, it is morally, ethically and probably legally appropriate for him to inform the patient. The patient can then voluntarily decide whether to allow the surgeon operate on him or not. 
56 Journal of Medicine and Biomedical Research

\section{CONCLUSION}

The threats of HIV/AIDS to health are obvious. But the medico-legal aspects appear to have been overlooked and neglected. Enlightenment on these aspects should be given their pride of place especially now that most patients are getting increasingly aware of their rights. This will help to prevent unnecessary litigations. It should be noted however that Surgeons also have their own rights and which ought to be protected. In view of the possibility of a small percentage of HIV positive patients being in their 'window period' it is advisable and indeed safer for Surgeons to always assume their patient to be HIV positive and adopt the universal precaution guidelines. There is need to have clear cut hospital policies on the ways HIV/ AIDS patients should be managed and a breach should attract stiff penalties. A reorientation is imperative to sensitive surgeons towards developing patients-friendly disposition to patients who are living positively with HIV/AIDS. The relevant bodies and other stake holders in the control, care and management of HIV positive patients needs to step up enlightenment campaigns on the need to accept victims without any form of discrimination. A pragmatic prosecution of the foregoing proposals will make health care delivery and the entire citizenry the better for it.

\section{References}

1 Van Wyk .C. AIDS: some medical-legal aspects. Med LAW 1991; 10 :139 - 53.

2 Ojule AC, Ejele OA, Opurum HC. HIV infection: risk of occupational exposure in a chemical pathology in Nigeria. Niger Postgraduate Med Joumal 2001; 8 : 78- 80.

3. Kothari Bk, Goyal S. Clinical profile of AIDS. J Association Physicians India 2001; 33: $136-42$.

4 Kumarasamy N, Solomon S, Flamgan TP, Hemalatha R, Thyagarajan SP, Mayer $\mathrm{KH}$. Natural history of Human Immudenficency Virus disease in Southern Indian. Clin Infection Dis 2003; $36: 79-85$.

(0 CMS UNIBEN JMBR 2006; 5(1): 51-57
5. Schecter WP. Surgical care of the HIV infected patients : a moral imperative. Camb Q. Health Ethics 1992; 1: 223 - 228.

6. Adelekan ML, Jolayemi SO, Ndom RJ. Caring for people with AIDS in Nigeria Teaching Hospital: Staff attitudes and knowledge. AIDS care 1995; 1 : $63-7$

7. Harris HW, Schecter WP. Surgical risk assessment and management in patients with HIV disease. Gastrointestinal Clin. North Am. 1997; 26377 - 391.

8. Adebamawo CA, Ezeome ER, Ajuwon JA, Ogundiran. The survey of the knowledge, attitude and practice of Nigerian Surgery trainees to HIV infected persons and AIDS patients. BMC Surg. 2002; 2-11

9. Gruskin S. Tarantola A. HIV/AIDS and human rights revisited. On HIV AIDS policy Law. Rev 2001; $6: 24-29$.

10. Cameron E. Legal rights, human rights and AIDS: the first decade. Report from South Africa AIDS Anal Afr 1993; 3 - 4.

11. Osime OC, Okojie O, Osadolor FO, Mohammed S. Informed Consent: Current pratices and medio-legal implications. E Afr Med J. 81, 331 - 335.

12. Orji EO, Ogunniyi sO. The case against mandatory preoperative HIV screening in Africa. Niger. J Med 2001; 10: 162- 4.

13. Savarit D, Decock KM, Schutz R, Konate S, Lackritz E, Bondurand A.Risk of HIV infection from transfusion with blood negative for HIV antibody in West Africa City. BMJ 1992; 305:498 - 502.

14. Breo D, Koop D. Calls for AIDS test before surgery. Am Med News 1987; 17-21.

15. Eke N, Jamabo RS, Adotey JM, Jebbin NJ. HIV Positive patients and the surgeon. Nig J Med 2004; 13: $366-71$.

16. Balasonbrahmanyan $\mathrm{V}$. Health care and human rights. AIDS Asia 1995; 2:17-21.

17. Onotai LO, Nwaorgu OG, Okoye BC. Ethical issues in HIV/AIDS infections. Niger. J Med $2004 ; 13: 282-285$.

18. FOO E, Sim R, Lim HY, Chan ST, Leo YS, Wong SY. Abdominal surgery in Human Immunodeficiency Virus (HIV) infected patients early local experience. Ann Acad Med Singapore 1998; 27: $759-62$. 
19. Marshall SE. Doctors' rights and patients obligations. Bioethics 1990; 4: 292 - 310

20. Annas GJ. Legal risks and responsibilities of physicians in the AIDS epidemic. Hastings Cent Rep 1988; 18: 26 - 32.

21. Article 3 of the Declaration of Human Rights, 1948

22. International Convention on Civil and Political Rights 1966.

23. The European Convention on Human Rights, 1969

24. Article 4 of The Africa Charter on Human and Peoples Rights, 1981

25. Section 33 of the 1999 constitution of the Federal Republic of Nigeria.

26. Section $17(3$ ) (a) and (c) of the 1999 constitution of the Federal Republic of Nigeria.
27. Background paper prepared for the commission on sustainable development; World Health Organisation Publications, March 1994.

28. Section 42 (2) of the 1999 constitution of the Federal Republic of Nigeria.

29. Department of Health. Guidelines on postexposure prophylaxis for health-care workers occupationally exposed to HIV. London: DOH, 1997.

30. Canadian AIDS Society (1990). Managing HIV and AIDS in the Canadian workplace. Part A: Guide for Manager, Part B: Manual for employee education.

31. Denning L J. In : General Cleaning Contractors Ltd V Christmas (1953), A.C. 180. 